\title{
Shaping of Local City Image under New Media Context
}

\author{
Shuo Chen \\ School of Humanity and Law \\ Nanyang Institute of Technology \\ Nanyang, Henan, China 473004
}

\begin{abstract}
The globalization and information in 21st century have brought unprecedented opportunities and challenges to mankind. In order to stand out from the competition, cities around the world gradually begin to pay attention to city image construction and take it as an important bargaining chip in the competition between cities. It is wellknown that city image construction has provided powerful impetus and support for the development of the city and plays a vital role in the accumulation of human resources and social capital. But under the impact of new media, the existing communication mode cannot meet the demands of city image any more. In order to realize the maximization of the communication effect of city image, we must start from three aspects of communication subject, communication media and communication content to better shape the image of city brand and improve city's competition power.
\end{abstract}

Keywords—omnimedia; city image; Nanyang; communication

\section{THE MEANING OF CITY IMAGE AND NECESSITY OF IT S NEW MEDIA COMMUNICATION}

As the impression and views of people for the city, city image is related to all aspects of connotation. We think that city image is "comprehensive impression and overall feeling given by the city for people, not only a kind of objective existence of the society, but also a kind of subjective social evaluation." A complete city image is a real reflection of city's physical space as well as city space with symbolism and imagination, and it can be divided into "physical image" and "virtual image". To sum up, city image refers to the total impression formed by social public for cognition of the city that uses many elements such as natural environment, economic development level, state of public security, building landscape, commercial trade, education of science and technology and perfection degree of all kinds of public facilities, government administrative patterns, historical and cultural tradition, values and quality of life of urban residents, etc. Shaping city brand image helps to improve city's competition power, widely attract more available social resources, promote comprehensive and healthy, social and economic development of the city as well as improve the comprehensive strength of the city. City is in the media and the impression of people. Because new media communication directly dominates the construction and communication of city's virtual image and positively has an influence on the public's perception and overall evaluation of the city, it plays a leading role in construction and communication of city image and the "image competition" between cities.

The arrival of new media age makes media environment and public opinion environment of city image communication have earth-shaking changes, which provide more abundant resources and wider space for the construction and communication of city image, and bring more severe challenges. In current social trend of informatization, the communication of city image must be supported by new media. Both of them supplement each other and develop together.

\section{ST ATUS ANALYSIS OF LOCAL CIT Y IMAGE COMMUNICATION UNDER NEW MEDIA CONTEXT}

Local city faces a lot of problems in the development of itself. On one hand, it has to compete with first-tier cities and second-tier cities; on the other hand, it also faces extrusion of similar cities with common characteristics. In the fierce competition among cities, it is related to the overall development of the city that how local city can make full use of new media and shape city image according to self-features Nevertheless, at present, many cities have vague understanding and practice dislocation of city image construction. The modernization construction of cities has the phenomenon that "all cities have the same image" and it is difficult to form urban landscape characteristics and cultural connotations. City image has no obvious local feature and many problems still exist.

\section{A. Confused Positioning of City Image}

An attractive city should be suitable for people to live, do business, enjoy the sight and recreate and has free and diverse choices on material life and spiritual life. But when we shape city image, almost all the cities interpret modern city landscapes as tall buildings, wide streets, squares, interchange bridge, brightness, lawns and the tidiness and newness commonly presented under this style and feature. Besides, the communication and positioning of city image have conflicts with products of city image and they are uncoordinated; dislocations often appear in propaganda form. 
The core value of city brand cannot be conveyed effectively, so urban competitiveness will be discounted greatly as well.

\section{B. The Culture of City Image Lacks Individuality and Local Characteristics of the City Are Shaped Insufficiently}

The cultural individuality of city image is unique feature and characteristic of a city different from other cities, an important basis for the public to identify and perceive a city as well as important part of city image. City image appears the phenomenon of severe homogeneous development. The cultural development of city image lacks individuality and is short of the shaping of local characteristics for cities. We should shape city image from several aspects: time-local historical line of a city, space-local memory storage of a city, ceremony-local inheritance and support of a city, narrative words - local symbol interpretation of a city.

\section{The Advertisement of City Image Is Boring and the Force of Creative Communication Is Weak}

Most advertising communication works of city image in our country lack real originality. Most of them narrate directly and straightforward, and publicize widely, which is difficult for customers to distinguish, perceive and understand. They don't know the core content that city advertisement film wants to convey on earth. Promotional film of Nanyang city, advertising video of Great Beauty Nanyang, promotional video of tourist attractions in Nanyang, advertising video of Nandu ancient city in Nanyang, all of these advertising videos skim over the surface of city landscape and the method of photographing still stays in the level of scenic sightseeing. Although the picture is excellent and beautiful, it still gives us the feeling that we seem to have met them before. The pattern of manifestation lacks innovation, so it will inevitably cause weak creative communication force. We should make full use of new media and deploy strategic planning of city image systematically and innovatively from the overall situation and full of characteristics. Only this can we make the content of communication full and well-rounded and make the communication of city image get the promotion that is coordinated with the development.

\section{COUNTERMEASURES OF CIT Y IMAGE COMMUNICATION UNDER NEW MEDIA CONTEXT}

\section{A. Communication Subject-From Government Communication to Communication of All the People}

The communication subjects of city image mainly include government sector in cities, professional groups and urban residents. In the era of mass communication, public sectors in cities represented by city government are the leading promulgator of city image in Nanyang. Under new media context, the balanced strength between communication subjects also change accordingly as media structure changes. The most prominent is the decline of government dominance and the sharp rise of the public influence. Therefore, the communication subject of city image should be a government-led organic integrity that professional association and all the people participate jointly and cooperate with each other.

1) Government-leader of city image shaping. Even though city image shaping needs the involvement of all the people, government plays decisive roles of "pacemaker" and "the person who make the final check" in it. In the spread of new media such as internet and mobile phone, on one hand, the government should make their voice heard through web portals, official microblog; on the other hand, the government should actively listen to public opinion and show respect for ordinary people, at the same time, correctly and actively guide them and make the media play a positive role in city image shaping.

2) Specialized personnel-impeller of city image shaping. Professional person refers to organizations and individuals who have communication technologies and experience in the process of city image communication, such as cultural media enterprises, scholars and specialists, etc. If we say government is the pacemaker of city image shaping, professional person is the impeller of city image shaping. Professional person can implement the concept of government and at the same time gain themselves the trust of ordinary people. They are opinion leaders in network communication and have higher reliability and popularity. In city image communication, we should pay attention to cultivating opinion leaders and let people know the image of city through their interpretation. These professional persons should also consciously take their responsibilities in city image shaping.

3) Common people-participants of city image shaping. As the "grass roots" strength in urban communication, common people play a bigger and bigger role in new media communication and they should be highly valued. In past traditional media transmission, most city image communications are the act of government and common people have weaker speaking rights and they can only passively accept relevant information of city image spread by the media and without effective feedback. Since the appearance of new media, it gives common people the rights of information communication. Each new media user has the right to obtain and release information. New media respects the dominant position of each common people and gives them the space of free involvement and make city image communication more freely, more timely and have more creativity. Common people are the spreaders as well as perceivers of city image. If city residents have no sense of belonging and identification for the city, the local characteristics of city image will not exist. But because common people have different individual qualities and the information is numerous and sundry, the information spread by common people is short of authority and reliability and sometimes it has side effects on city image. We should respect grassroots communications, at the same time, strengthen the management, guidance and education and make this force that cannot be underestimated move forward on the right track 


\section{B. Communication Media-Form Joint Forces in Integration}

City image communication is a complex project and it is difficult to achieve the ideal effect through relying on single communications media. Under the environment of new media, on one hand, the requirements of communication are lowered and the absolute amount of information increases sharply, but excessive information greatly distracts the attention of common people. On the other hand, the acquisition channel of information of the public increases day by day and the difficu lty of subdivision of audiences also grows increasingly. Therefore, each communication means has its limitation on the mode of transmission and communicating effect and it cannot cover the vast majority of the target audiences. So in order to achieve better effect, city image communication must comprehensively use various transmission methods and carry out integrated communication. The integrated communication of city image should not only give full play to the function of dissemination of multiple media, but also guide different media to communicate and cooperate with each other. We should fully arouse the advantages of available media and use communication channels of city image to integrate reasonably to promote the pertinence, coverage rate and arrival rate of transmission and improve the communication effect.

1) Internet-Strengthen the construction of website. As the new media with the most dramatic development, internet is an important tool of city image communication and a channel that must be used and made good use of. On the internet, we should design communication website and special subject web page, systematically spread all aspects of information about the construction and development of the city and highlight the advantageous characters and timely update pages and perfect the function of website. Besides, we can create propaganda pages of special subject of this city in the tourism and classification column of some big web portals, meanwhile, establish a large number of search engines to increase page view and expand the influence surface. For example, open travel blog circles in Sina, spread the tourism image of the city through the form of blog. We should pay attention to the construction and maintenance of the website and be friendly to visitors. Web-interface should conform to aesthetic appreciation of the masses and the tone should be unified; optimize key words and the description; add ALT and TITLE attributes to the picture, which can bring SEO effect and facilitate visual disabilities to browse the webpage; the optimizations of internal lin ks include the correlation of links, anchor te xt links, and linked pages of all navigations, checking the code error, avoiding dead links, repeating links and links of irrelevant information; external links should try to keep the diversity of links; friendly links should be websites that have higher relevance and better overall quality. It can improve keywords ranking, increase the website traffic and more widely spread the city image of Nanyang.

2) Microblog-Center of network consensus. City administrators should put great emphasis on microblog. Microblog of government affairs should listen carefully to the voice of net citizens and actively respond to the demands of internet users, guide net citizens to transfer public opinion demands from the internet to reality and solve through institutionalized way; promote smooth communication and benign interaction between government and the public on the internet through microblog; leaders and officials in the government should actively use microblog to learn correct methods to communicate and interact with the public and strengthen the abilities of using microblog to work and release information to achieve the goal of helping government to improve work efficiency. The microblog of Tourist Administration should learn the experiences of microblogs of developed tourism cities; with the help of text, pictures and videos, it can show the unique charm and strengthen the communication and interaction with net friends and implement some microblogging marketing activities such as "pay attention to and repost before draw a lottery"

3) WeChat-Pay greater attention to WeChat. In October 2013, WeChat users have reached 600 million. The 600 million of users are completely based on mobile terminal and Smart Phone, which is more meaningful than over 500 million of registered users on Sina microblog and over 500 million of active users on QQ. The most important feature of WeChat is that it creates emotional links with audiences and has user viscosity that is difficult for other platforms to achieve. There is no reason to neglect this platform. Each city should open WeChat public number as soon as possible and enhance the efficiency of city image communication through urban marketing by pushing information on WeChat.

\section{Communication Content-Highlight Local Characteristics of the City}

Individuality of a city is the peculiarity that is different from other cities, the most effective communication content and also the foundation of urban sustainable development. Only with distinct individuality can a city have communication value, get the attention from people and produce cohesive force and let citizens have a sense of pride and devote their enthusiasm to living here. Individualities of a city are the unique historic culture, natural landscape and city life. The shaping of city image is to create a real local city with local characteristics by renovating city block, buildings, holidays and meetings of the city, famous persons in the city and city brands, etc. according to its own characteristics.

1) Culture-historical sediment of local characteristics of city image. In the long historical process, with the time pass by, each city has left many people, things and objects, which form the historic culture of this city and affect the spiritual world of people who live in this place. These unique cultures generated in some specific place embody the local characteristics of city image and it is an important part for us to spread local image of a city. Take Nanyang in Henan province as an example, Nanyang has a good reputation and is known as "Nandu" and "Dixiang"; tremendous amount of celebrities come forth here. In history, it has nourished many ancient celebrities such as Baili $\mathrm{Xi}$, the famous prime minister (in feudal China), Fan Li, the sage of business, 
Zhang Zhongjing, the medical sage, Zhang Heng, the sage of science, Zhuge Liang, the sage of wisdom. In modern times, some outstanding persons spring out, such as Feng Youlan, the philosopher, Peng Xuefeng, the militarist, Eeryuehe, the writer, Wang Yongming, the inventor, etc. There are 107 State Protected Historic Sites and Provincial Heritage Conservation Unites in Nanyang, such as Zhuge Liang Memorial Hall, Museum of Han Stone Relief, Neixiang Local Magistrate's Office, Shan xi and Shaanxi Commercial Guild Hall in Sheqi, a Street of Jingzi Pass, etc. These historic cultures edify Nanyang people from generation to generation and influence their spirit and mind. They are not only a kind of external city images, but also a kind of inherent spirits of Nanyang people. In the city image communication of Nanyang, the image of Nanyang full of long cultures can be acknowledged widely by Nanyang people.

2) Landscape-natural quality of local characteristics of city image. A city is a flow of space, place and landscape and shapes the place identification of residents. Sometimes human survival is to look for a sense of place belonging. Urban space can be the reflection of personal feelings and has the meaning of culture symbol as well as affective meaning. In the process of media transmission, as symbols to store the collective memory of urban residents, geographic elements in the city provide platforms for people to do public intercourse and have an irreplaceable and important significance in the city. Equally, take Nanyang in Henan province as an example, Nanyang is located in the transition region from subtropical zone to warm temperature zone, and it is the natural watershed of Yangtze River, Yellow River and Huaihe river, with four distinctive seasons and excellent ecology. The scenic landscape combines characteristics of the south and the north. Bao Tianman, Laojieling, Fossil Coenosis of Dinosaur Eggs, the Source of Huaihe River, Tongbai Mountains, White River, all these places have become shiny city cards. Especially the Danjiangkou Reservoir, the location of channel origin of the Middle Route Project of South-to-North Water Division, has a wide expanse of mist-covered waters and watery blue reaches far beyond the horizon. It has become the focus of attraction at home and abroad. It is not only a kind of natural image, but also contains the spirit image of Nanyang people who make selfless contribution to our country and make enormous sacrifice and contribution to South-to-North Water Diversion Project. In addition, Liberation Square and Datong Department Store, etc. are spatial carriers of city image of Nanyang that bears the memories and feelings of Nanyang people. All of these are natural expressions of local characteristics in the image of Nanyang city.

3) Activity-ceremony bearings of local characteristics of city image. For the dimensionality of ceremonies, it mainly contains the sharing and cohesion in the city shaped through media events and media ritual. Ceremonies are specific social and cultural coding events, activities or collective behaviors that have participation, procedure and performance, spreading the important roles played in the representation of common belief and the maintenance of society. Except for some specific large-scale activities and major news events, media ritual also includes reports of daily life. Under the omnimedia environment and in the publicity of city image, except for presenting natural sceneries and historic culture, we should also pay attention to the feelings and opinions of citizens. Cognition, experience and firsthand feelings of local citizens and people from other places should be important parts of city image.

\section{CONCLUSION}

City image is of great significance to the urban development. For the shaping of city image under new media context, on one hand, it should highlight individuality of the city and look for unique features from history, nature and activities; on the other hand, it should make full use of new media and integrate systematically from the communication subject to communication ways of medium according to the characteristics of new media.

\section{REFERENCES}

[1] Sun Wei. Shanghai Reengineering: Urban Research under Perspective of Communication [J]. Journal of Hangzhou Normal University, 2013 (3): 76 82

[2] Shao Peiren. Temperature of Local Place - Social Construction and Cultural Memory of Media Geography Elements [J], Journal of Jiangsu Normal University, 2010(9):32 36

[3] Zhou Yan. Research on Urban Communication Ideas and Paths [J], Contemporary Communications, 2012(3): 28 33.

[4] Chen Ying, Dong Tiance. Shaping of Local Media and City ImageReappearance, Field or Identity [J], Urban Insight, 2012(1): 47 52

[5] Ye Xiaobin. Research on Mass Media and City Image Communication [D], Wuhan: Wuhan University. 2010:50

[6] Wang Shuo. Research on Current Situation and Promotion Strategy of City Image Communication [D], Shenyang: Liaoning University. 2013:14 